Gelanggang Pendidikan Jasmani Indonesia

\title{
PROFIL KEBUGARAN JASMANI PEMAIN SEPAKBOLA METRO FC MALANG
}

\author{
Hariyoko $^{1 \bowtie}$, Prayogi Dwina Angga ${ }^{2}$, Fahrial Amiq $^{3}$, Eko Hariyanto ${ }^{3}$ \\ Universitas Negeri Malang \\ hariyoko.fik@um.ac.id
}

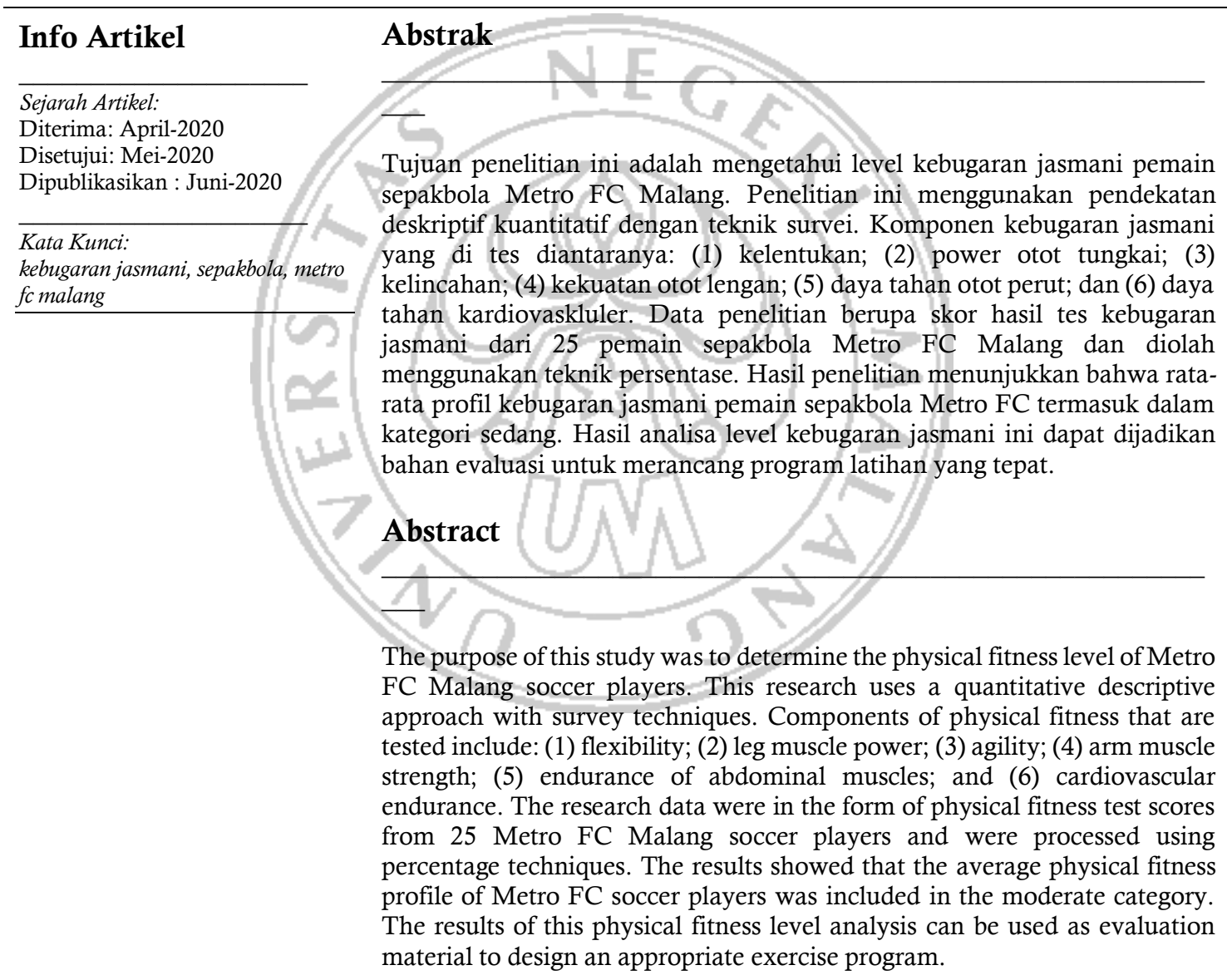

(C) 2020 Universitas Negeri Malang

Alamat korespondensi:

E-mail: hariyoko.fik@um.ac.id

ISSN: 2614-8293 (Online)

\section{PENDAHULUAN}

Kebugaran jasmani atau aspek fisik adalah salah satu aspek terpenting dari kinerja dan performa dalam sebuah permainan sepakbola (Helgerud dkk., 2011), beberapa ahli mengatakan 
bahwa berbicara mengenai sepakbola berarti berbicara mengenai kebugaran jasmani (Al Haddad dkk., 2015; Boone dkk., 2012; Matkovi \& Mi, 2003). Selain itu, dalam beberapa tahun terakhir, faktorfaktor lain seperti teknik, taktik, dan psikologi juga telah menjadi perhatian (Barrett dkk., 2018; Botek dkk., 2014; F. M. Clemente dkk., 2017; M. F. Clemente dkk., 2013; Dragijsky dkk., 2017). Seorang pemain sepakbola profesional yang terampil akan ikut serta dalam sebuah permainan secara penuh, sehingga aspek kebugaran jasmani menjadi aspek yang akan saling melengkapi dengan keterampilan seorang pemain sepakbola. Durasi potensial dalam sebuah permainan sepakbola adalah 90 menit dengan kemungkinan babak tambahan selama 30 menit sehingga total ada 120 menit. Dalam sebuah permainan, dapat dilihat dengan mudah bahwa pemain sepakbola beraksi selama hampir dua jam atau lebih jika dilanjutkan dengan tendangan penalti yang merupakan bagian paling sulit untuk semua pemain ketika pemain sudah mengalami kelelahan dan berada di bawah tekanan, sehingga kemungkinan terjadinya cidera juga lebih besar.

Seorang pemain sepakbola harus melakukan berbagai gerakan yang kompleks mulai dari berlari, melompat, menyundul, menembak dan lain sebagainya. Seluruh gerakan tersebut harus dilakukan oleh seorang pesepakbola dengan sempurna dan berkali-kali selama pertandingan berlangsung sehingga hanya pemain sepakbola yang memiliki kondisi kebugaran jasmani yang baiklah yang akan mampu melakukan semuanya. Beberapa tuntutan utama kesiapan kebugaran jasmani yang harus dipenuhi dalam sebuah permainan sepakbola diantaranya power, kekuatan, keseimbangan, stabilitas tubuh, fleksibilitas, dan daya tahan yang memadai (Al Haddad dkk., 2015; Di Salvo dkk., 2007; Matkovi \& Mi, 2003) (J Helgerud dkk., 2001) (J Bloomfield dkk., t.t.). Selain itu, Bangsbo (J. Bangsbo, 1994) menekankan bahwa agar mampu bersaing, menjadi pemain sepakbola yang sukses serta kompetitif, maka pengembangan kecepatan, kelincahan, kekuatan dengan kombinasi kemampuan aerobik dan anaerob (bahkan maksimal) menjadi sebuah prioritas utama. Apabila dianalisis lebih lanjut, ternyata berlari bukan satu-satunya aspek utama dalam sepakbola. Meskipun dalam berbagai kondisi permainan, seorang pemain dapat berlari hingga 10 kilometer. Bahkan dalam 90 menit, pemain berlari dengan kecepatan yang bervariasi, juga bisa berganti arah berlari hingga 1000 kali.

Sesuai dengan perkembangan dalam taktik sepakbola, beberapa gaya permainan sepakbola juga mengalami perkembangan seperti gaya permainan yang menuntut pemain untuk lebih banyak berlari dalam sebuah permainan. Sebagai contoh, gaya permainan yang dilakukan oleh tim-tim di Eropa lebih banyak menggunakan sentuhan-sentuhan cepat, satu sampai tiga kali sentuhan digunakan dan bahkan tempo permainan juga diperlambat. Berdasarkan analisis tersebut maka dalam permainan sepakbola tidak hanya terfokus pada berlari, namun memiliki tuntutan komponen kebugaran lainnya guna menunjang permainan yang baik.

Telah terbukti secara ilmiah bahwa seorang pemain sepakbola cenderung lebih banyak melakukan kesalahan ketika mengalami kelelahan. Pemain sepakbola akan kehilangan berbagai peluang dan banyak melakukan kesalahan apabila tidak memiliki tingkat kebugaran jasmani yang tinggi. Seperti yang dilakukan oleh Sir Alex Ferguson, selalu melakukan tes kebugaran jasmani pada setiap pemain di pagi hari sebelum pertandingan, sehingga hasil ilmiah dijadikan dasar untuk memutuskan siapa pemain yang siap untuk bertanding. Beberapa penelitian menarik kesimpulan bahwa usia, morfologi, dan kebugaran jasmani merupakan parameter yang berpengaruh terhadap performa pemain sepakbola tingkat elit (A1 Haddad dkk., 2015; Di Salvo dkk., 2007; Matkovi \& Mi, 2003), namun semuanya akan sangat bergantung pada posisi bermain. Penelitian secara mendalam yang bertujuan untuk mengetahui dan mengkaji kebugaran jasmani pemain sepakbola professional, kemungkinan akan berpengaruh besar pada program latihan harian dan peningkatan performa fisik yang dimiliki pemain.

\section{METODE}

Pendekatan deskriptif kuantitatif yang digunakan dalam penelitian ini dilakukan dengan teknik survei, dan responden yang digunakan adalah semua pemain sepakbola Metro FC Malang yang berjumlah 25 orang.

Instrumen yang digunakan dalam penelitian ini dikhususkan untuk mengukur komponen kebugaran jasmani dalam permainan sepakbola, yang terdiri dari: (1) Tes flexometer untuk mengukur kelentukan, (2) Standing long jump test untuk mengukur power otot tungkai, (3) Illinois agility test untuk mengukur kelincahan, (4) Tes lari 30 meter untuk mengukur kecepatan, (5) Tes push-up untuk mengukur kekuatan otot lengan, (6) Tes sit-up untuk mengukur ketahanan otot perut, (7) Yoyo test 
untuk mengukur daya tahan kardiovaskular. Kemudian data yang terkumpul dikonversikan ke dalam norma kategori masing-masing jenis tes.

Berdasarkan tujuan penelitian ini, maka digunakan teknik analisis persentase. Data yang terkumpul dari masing-masing jenis tes, setelah diubah menjadi T-skor dan ditotal nilainya, kemudian dikonversikan ke dalam tabel norma kebugaran jasmani pemain sepakbola Metro FC Malang (lihat Tabel 1), dan selanjutnya dianalisis dengan persentase.

Tabel 1. Norma Kebugaran Jasmani Pemain Sepakbola Metro FC Malang

\begin{tabular}{cccc}
\hline No & \multicolumn{2}{c}{ Interval Tingkat Kebugaran Jasmani } & Kategori \\
\hline 1 & $\bar{X}+1,5$ SD Ke atas & $>396,31$ & Sangat Baik \\
2 & $\bar{X}+0,5$ SD s/d $\bar{X}+1,5$ SD & $365,44 \div 396,31$ & Baik \\
3 & $\bar{X}-0,5$ SD s/d $\bar{X}+0,5$ SD & $334,56 \div 365,44$ & Sedang \\
4 & $\bar{X}-1,5$ SD s/d $\bar{X}-0,5$ SD & $303,69 \div 334,56$ & Jelek \\
5 & Kurang dari $\bar{X}-1,5$ SD & $<303,69$ & Sangat Jelek \\
\hline
\end{tabular}

\section{HASIL}

Deskripsi hasil analisis data tingkat kebugaran jasmani dari 25 pemain sepakbola Metro FC Malang disajikan dalam rincian berikut: (1) komponen kelentukan dengan rentangan skor antara 16,20 sampai dengan $30,80 \mathrm{~cm}$, diperoleh rata-rata (mean) sebesar $22,18 \mathrm{~cm}$, standar deviasi (SD) sebesar 4,63, dan termasuk dalam kategori "baik sekali", (2) komponen power otot tungkai dengan rentangan skor antara 220 sampai dengan $300 \mathrm{~cm}$, diperoleh rata-rata (mean) sebesar $248 \mathrm{~cm}$, standar deviasi (SD) sebesar 23,45, dan termasuk dalam kategori "baik", (3) komponen kelincahan dengan rentangan skor antara 19,84 sampai dengan 17,47 detik, diperoleh rata-rata (mean) sebesar 18,71 detik, standar deviasi (SD) sebesar 0,63, dan termasuk dalam kategori "kurang", (4) komponen kecepatan dengan rentangan skor antara 5,10 sampai dengan 3,89 detik, diperoleh rata-rata (mean) sebesar 4,46 detik, standar deviasi (SD) sebesar 0,29, dan termasuk dalam kategori "sedang", (5) komponen kekuatan otot lengan dengan rentangan skor antara 13,00 sampai dengan 78,00 kali, diperoleh ratarata (mean) sebesar 39 kali, standar deviasi (SD) sebesar 14,37, dan termasuk dalam kategori "sedang", (6) komponen ketahanan otot perut dengan rentangan skor antara 33,00 sampai dengan 78,00 kali, diperoleh rata-rata (mean) sebesar 58,68 kali, standar deviasi (SD) sebesar 10,48, dan termasuk dalam kategori "baik", (7) komponen daya tahan kardiovaskular dengan rentangan skor antara 48,02 sampai dengan $51,28 \mathrm{ml} / \mathrm{kg} / \mathrm{min}$, diperoleh rata-rata (mean) sebesar $49,12 \mathrm{ml} / \mathrm{kg} / \mathrm{min}$, standar deviasi (SD) sebesar 0,92 , dan termasuk dalam kategori "baik sekali".

Adapun hasil analisis data tingkat kebugaran jasmani secara keseluruhan, diketahui bahwa kebugaran jasmani dari 25 pemain sepakbola Metro FC Malang dengan rentangan skor antara 307,79 sampai dengan 411,19, diperoleh skor rata-rata (mean) sebesar 350,00, standar deviasi (SD) sebesar 30,87 , dan termasuk dalam kategori "sedang".

\section{PEMBAHASAN}

Hasil penelitian ini menunjukkan bahwa rata-rata profil kebugaran jasmani pemain sepakbola Metro FC termasuk dalam kategori "sedang". Dari beberapa komponen kebugaran jasmani yang diteliti, ada yang sudah termasuk dalam kategori "baik" dan "baik sekali", yaitu kelentukan, power otot tungkai, ketahanan otot perut, dan daya tahan kardiovaskular. Namun, masih ada beberapa komponen kebugaran jasmani yang termasuk dalam kategori di bawah "sedang", yaitu kelincahan, kecepatan, dan kekuatan otot lengan.

Padahal, berdasarkan penemuan ilmiah dari Weineck, penampilan seorang pemain sepakbola saat ini ditentukan oleh banyak faktor yang saling terkoordinasi, yang salah satunya adalah faktor kebugaran fisik (Barrett dkk., 2018; Dost dkk., 2016; Unnithan dkk., 2012). Selain itu, agar mampu menjadi pemain sepakbola yang sukses serta kompetitif, maka pengembangan kecepatan, kelincahan, kekuatan dengan kombinasi kemampuan aerobik dan anaerob (bahkan maksimal) menjadi sebuah prioritas utama (Pigozzi dkk., 2006, 2006; Sporis dkk., 2009). Seorang pemain sepakbola juga dituntut untuk memiliki kondisi fisik atau kebugaran jasmani yang prima, karena sangat menunjang 
penampilannya saat bermain (Andersson dkk., 2016; Castagna dkk., 2003; Heron \& Cupples, 2014; Michailidis, 2018). Seorang pemain sepakbola mempunyai beberapa keuntungan jika kondisi fisiknya baik, antara lain cukup mampu dan tidak banyak mengalami kesulitan untuk mempelajari keterampilan sepakbola yang relatif kompleks, tidak mudah lelah ketika mengikuti latihan atau pertandingan, dapat menyelesaikan materi program latihan tanpa adanya banyak kendala, serta mampu menyelesaikan latihan yang berat.

Kebugaran fisik merupakan salah satu elemen utama yang berpengaruh terhadap kinerja tim dalam sebuah pertandingan sepakbola, hal tersebut disebabkan tuntutan kebutuhan fisik dan determinasi yang tinggi selama pertandingan berlangsung (J. Bangsbo dkk., 2006; Stølen dkk., 2005). Dalam sebuah pertandingan sepakbola, seorang pemain paling tidak harus melakukan 150-250 gerakan intens seperti: tackles, heading, cutting dan sprinting (Bujnovky dkk., 2019; Chamari, 2005; Stølen dkk., 2005). Dalam sebuah pertandingan sepakbola, lari sprint setidaknya dilakukan setiap 90 detik dengan waktu tempuh selama 2 sampai 4 detik dalam sekali sprint. Apabila dihitung dalam waktu efektif, maka sprint bisa mencapai total $0,5-3 \%$ dari seluruh waktu efektif yang digunakan selama pertandingan (Mohr dkk., 2003). Tidak kalah pentingnya juga komponen daya ledak dan kontraksi otot yang kuat guna menjaga keseimbangan tubuh dan mengontrol bola adalah sebuah situasi yang sangat umum dalam sebuah pertandingan sepakbola (Chan dkk., 2016). Komponen fisik lain yang juga sangat berperan penting dalam sepakbola adalah daya tahan (Bujnovky dkk., 2019; Chamari, 2005; Hoff, 2005; Sporis dkk., 2009), dalam sebuah pertandingan sepakbola setiap pemain setidaknya harus menyelesaikan jarak 8 sampai 12 kilometer dengan intensitas kerja rata-rata antara 80-90\% dari denyut jantung maksimal. Bloomfeld juga mencatat bahwa pesepakbola pria yang bermain pada level profesional dapat menempuh total jarak 9-14 dalam sebuah pertandingan ( $\mathrm{J}$ Bloomfield dkk., 2007).

Kompetisi dan pertarungan ketat pada sepakbola modern akhirnya menuntut kondisi fisik yang sangat tinggi dan harus disertai dengan kemampuan adaptasi fisiologis tubuh guna menunjang performa yang bagus untuk dapat bemain selama 90 menit tanpa lelah. Kebugaran jasmani atau kebugaran fisik inilah yang nantinya akan menjadi keunggulan bagi seorang pemain apabila dibandingkan dengan pemain lainnya (Faude dkk., 2013). Dampak lain dengan adanya kondisi kebugaran jasmani seorang pemain yang sangat baik adalah tingkat konsentrasi yang tidak mudah menurun selama pertandingan berlangsung. Pemain dapat menjalankan instruksi pelatih (M. F. Clemente dkk., 2013), tidak mudah terpancing emosi, serta tidak banyak melakukan unforced error atau kesalahan sendiri selama pertandingan berlangsung. Hasil penelitian menunjukkan bahwa kelelahan mental akibat pengaruh penurunan kondisi fisik maka akan dapat mengganggu konsentrasi dan pengambilan keputusan dalam sebuah permainan (Martin dkk., 2015). Oleh karena itu, komponen kebugaran fisik menjadi bagian penting dalam mempersiapkan sebuah tim sepakbola guna menunjang aspek taktik dan teknis lainnya.

Masalah kondisi fisik pemain sepakbola di Indonesia selalu menjadi persoalan utama yang klasik dan selalu berulang, tidak terkecuali pada Tim Nasional Indoensia. Hasil pengamatan peneliti menemukan bahwa keluhan pelatih yang menangani Tim Nasional selalu terletak pada kondisi fisik pemain. Namun memang perlu dipahami bahwa hasil kebugaran fisik seorang pemain tentunya berasal dari proses yang dilalui bersama klubnya serta masih minimnya literasi mengenai tanggung jawab seorang pemain dalam mengelola kondisi fisiknya. Penting bagi Metro FC sebagai tim sepakbola yang bermain pada level liga 2 pada liga profesional di Indonesia untuk mengetahui kondisi fisik atau bahkan kelemahan komponen fisik pada setiap pemainnya. Hasil analisa kondisi kebugaran jasmani ini akan menjadi bahan evaluasi dan tolak ukur bagi pelatih untuk menentukan karakteristik latihan yang disesuaikan dengan kondisi masing-masing pemain atau mengembangkan program latihan yang bersifat individual.

\section{KESIMPULAN}

Berdasarkan hasil penelitian, dapat diambil kesimpulan bahwa profil kebugaran jasmani pemain sepakbola Metro FC termasuk dalam kategori "sedang". Dari tujuh komponen kebugaran jasmani yang diukur dapat diketahui bahwa: (1) komponen kelentukan termasuk dalam kategori "baik sekali", (2) komponen power otot tungkai termasuk dalam kategori "baik", (3) komponen kelincahan termasuk dalam kategori "kurang", (4) komponen kecepatan termasuk dalam kategori "sedang", (5) komponen kekuatan otot lengan termasuk dalam kategori "sedang", (6) komponen ketahanan otot 
perut termasuk dalam kategori "baik", dan (7) komponen daya tahan kardiovaskular termasuk dalam kategori "baik sekali".

\section{DAFTAR PUSTAKA}

Al Haddad, H., Simpson, B. M., Buchheit, M., Di Salvo, V., \& Mendez-Villanueva, A. (2015). Peak Match Speed and Maximal Sprinting Speed in Young Soccer Players: Effect of Age and Playing Position. International Journal of Sports Physiology and Performance, 10(7), 888-896. https://doi.org/10.1123/ijspp.2014-0539

Andersson, P., Meander, S., \& Sinclair, J. (2016). Anthropometric and physical profiles in elite and sub elite Swedish male soccer players. INSTITUTIONEN FÖR KOSTOCH IDROTTSVETENSKAP, 34.

Bangsbo, J. (1994). Energy demands in competitive soccer. Journal of Sports Sciences, 12 Spec No, S512.

Bangsbo, J., Mohr, M., \& Krustrup, P. (2006). Physical and metabolic demands of training and matchplay in the elite football player.-Journal of Sports Sciences, 24(7), 665-674. https://doi.org/10.1080/02640410500482529

Barrett, S., McLaren, S., Spears, I., Ward, P., \& Weston, M. (2018). The Influence of Playing Position and Contextual Factors on Soccer Players' Match Differential Ratings of Perceived Exertion: A Preliminary Investigation. Sports, 6(1),13. https://doi.org/10.3390/sports6010013

Bloomfield, J, Polman, R., \& O'Donoghue, P. (t.t.). Physical demands of different positions in FA Premier League soccer. 8.

Bloomfield, J, Polman, R., \& O'Donoghue, P. (2007). Reliability of the Bloomfield Movement Classification. International Journal of Performance Analysis in Sport, 7(1), 20-27. https://doi.org/10.1080/24748668.2007.11868384

Boone, J., Vaeyens, R., Steyaert, A., Bossche, L. V., \& Bourgois, J. (2012). Physical Fitness of Elite Belgian Soccer Players by Player Position: Journal of Strength and Conditioning Research, 26(8), 2051-2057. https://doi.org/10.1519/JSC.0b013e318239f84f

Botek, M., Krejci, J., \& Weisser, R. (2014). Autonomic cardiac regulation and morpho-physiological responses to eight week training preparation in junior soccer players. Acta Gymnica, 44(3), 155163. https://doi.org/10.5507/ag.2014.016

Bujnovky, D., Maly, T., Ford, K., Sugimoto, D., Kunzmann, E., Hank, M., \& Zahalka, F. (2019). Physical Fitness Characteristics of High-level Youth Football Players: Influence of Playing Position. Sports, 7(2), 46. https://doi.org/10.3390/sports7020046

Castagna, C., D'Ottavio, S., \& Abt, G. (2003). Activity profile of young soccer players during actual match play. Journal of Strength and Conditioning Research, 17(4), 775-780.

Chamari, K. (2005). Endurance training and testing with the ball in young elite soccer players. British Journal of Sports Medicine, 39(1), 24-28. https://doi.org/10.1136/bjsm.2003.009985

Chan, H. C.-K., Fong, D. T.-P., Lee, J. W.-Y., Yau, Q. K.-C., Yung, P. S.-H., \& Chan, K.-M. (2016). Power and endurance in Hong Kong professional football players. Asia-Pacific Journal of Sports Medicine, Arthroscopy, Rehabilitation and Technology, 5, 1-5. https://doi.org/10.1016/j.asmart.2016.05.001

Clemente, F. M., Nikolaidis, P. T., Van Der Linden, C. M. I. N., \& Silva, B. (2017). Effects of SmallSided Soccer Games on Internal and External Load and Lower Limb Power: A Pilot Study in Collegiate Players. Human Movement, 18(1). https://doi.org/10.1515/humo-2017-0007

Clemente, M. F., Couceiro, S. M., Martins, F. M. L., Mendes, R., \& Figueiredo, A. J. (2013). Measuring Collective Behaviour in Football Teams: Inspecting the impact of each half of the 
match on ball possession. International Journal of Performance Analysis in Sport, 13(3), 678-689. https://doi.org/10.1080/24748668.2013.11868680

Di Salvo, V., Baron, R., Tschan, H., Calderon Montero, F., Bachl, N., \& Pigozzi, F. (2007). Performance Characteristics According to Playing Position in Elite Soccer. International Journal of Sports Medicine, 28(3), 222-227. https://doi.org/10.1055/s-2006-924294

Dost, H., Hyballa, P., \& Poel, H.-D. te. (2016). Soccer: Functional Fitness Training: Strength | Motor Skills | Speed | Endurance. Meyer \& Meyer Sport.

Dragijsky, M., Maly, T., Zahalka, F., Kunzmann, E., \& Hank, M. (2017). Seasonal Variation of Agility, Speed and Endurance Performance in Young Elite Soccer Players. Sports, 5(1), 12. https://doi.org/10.3390/sports5010012

Faude, O., Roth, R., Di Giovine, D., Zahner, L., \& Donath, L. (2013). Combined strength and power training in high-level amateur football during the competitive season: A randomised-controlled trial. Journal of Sports Sciences, 31(13), 1460-1467. https://doi.org/10.1080/02640414.2013.796065

Helgerud, J, Engen, L. C., Wisløff, U., \& Hoff, J. (t.t.). Aerobic endurance training improves soccer performance. Medicine \& Science in Sports \& Exercise, 1925-9131.

Helgerud, J, Rodas, G., Kemi, O. J., \& Hoff, J. (2011). Strength and endurance in elite football players. International Journal of Sports Medicine, 32(9), 677-682. https://doi.org/10.1055/s-00311275742

Heron, N., \& Cupples, M. (2014). The health profile of football/soccer players in Northern Ireland a review of the uefa pre-participation medical screening procedure. BMC Sports Science, Medicine and Rehabilitation, 6(1), 5. https://doi.org/10.1186/2052-1847-6-5

Hoff, J. (2005). Training and testing physical capacities for elite soccer players. Journal of Sports Sciences, 23(6), 573-582. https://doi.org/10.1080/02640410400021252

Martin, K., Thompson, K. G., Keegan, R., Ball, N., \& Rattray, B. (2015). Mental fatigue does not affect maximal anaerobic exercise performance. European Journal of Applied Physiology, 115(4), 715-725. https://doi.org/10.1007/s00421-014-3052-1

Matkovi, B. R., \& Mi, M. (2003). Morphological Differences of Elite Croatian Soccer Players According to the Team Position. Coll. Antropol., 8.

Michailidis, Y. (2018). Physical Condition Differences between Semi-Professional and Amateur Soccer Players. International Journal of Science Culture and Sport, 6(27), 191-202. https://doi.org/10.14486/IntJSCS743

Mohr, M., Krustrup, P., \& Bangsbo, J. (2003). Match performance of high-standard soccer players with special reference to development of fatigue. Journal of Sports Sciences, 21(7), 519-528. https://doi.org/10.1080/0264041031000071182

Pigozzi, F., Giombini, A., Fagnani, F., \& di Salvo, V. (2006). Evaluation of Whole Physical Condition. Dalam P. Volpi (Ed.), Football Traumatology (hlm. 33-41). Springer Milan. https://doi.org/10.1007/88-470-0419-5_4

Sporis, G., Jukic, I., Ostojic, S. M., \& Milanovic, D. (2009). Fitness Profiling in Soccer: Physical and Physiologic Characteristics of Elite Players: Journal of Strength and Conditioning Research, 23(7), 1947-1953. https://doi.org/10.1519/JSC.0b013e3181b3e141

Stølen, T., Chamari, K., Castagna, C., \& Wisløff, U. (2005). Physiology of Soccer. Sports Medicine, 35(6), 501-536. https://doi.org/10.2165/00007256-200535060-00004

Unnithan, V., White, J., Georgiou, A., Iga, J., \& Drust, B. (2012). Talent identification in youth soccer. Journal of Sports Sciences, 30(15), 1719-1726. https://doi.org/10.1080/02640414.2012.731515 
Hariyoko / Gelanggang Pendidikan Jasmani Indonesia 4 (1) (2020)

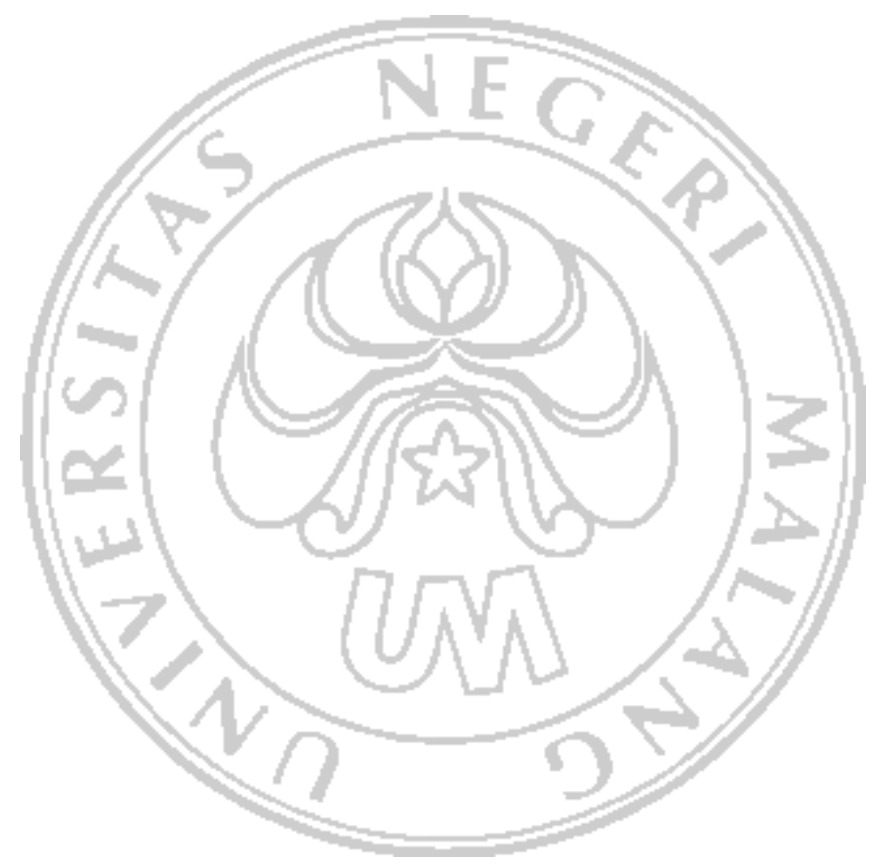

